\title{
Ranking Operations Management Conferences
}

\author{
Harm-Jan Steenhuis* \\ College of Business and Public Administration, Eastern Washington University \\ 668 N. Riverpoint Blvd., Suite A, Spokane, WA 99202, USA \\ E-mail: hsteenhuis@mail.ewu.edu \\ Erik-Joost de Bruijn \\ School of Management and Governance, University of Twente, \\ PO Box 715, 7500 AE, Enschede, The Netherlands \\ E-mail: e.j.debruijn@utwente.nl
}

\begin{abstract}
The purpose of this paper is to present a ranking of operations management conferences. Several publications have appeared in the field of Operations Management which rank related journals. Many academics also publish at conferences but we have not come across publications that rank conferences. Several ranking systems exist for journals based on, for example, perceived relevance and quality, citation, and author affiliation. . In this paper the first attempt is made in developing an operations management conference ranking based upon author affiliation. This is done in two steps. First, based on an analysis of contributions to operations management journals a ranking of affiliations is established. Then, this ranking is used to determine the author affiliation index for several conferences such as from the Production and Operations Management Society (POMS), European Operations Management Association (EurOMA), Operations and Supply Chain Management (OSCM), and the Operations Management Division of the Academy of Management (AoM). The results provide information for authors that help in deciding which operations management oriented conferences to attend. It was found that the AoM conference is on average the conference with the highest First Author Affiliation Index (FAAI) scores. It also scores the highest for the six journals combined in four of the six years. The POMS conference scored highest in three of the six years for the three US-based journals while the EurOMA conference scored highest in four of the six years for European-based journals. The findings can be used to make more informed decisions related to which operations management conference to attend based upon the assumption of quality of presented papers.
\end{abstract}

Keywords: operations management, conference rankings, journal rankings

\section{Introduction}

Most faculty members are required to publish research as part of their yearly workload. For example, faculty at Association to Advance Collegiate Schools of Business (AACSB) accredited institutions are required to maintain intellectual qualifications through, among other things, journal publications. Colleges can determine their own definitions of what is acceptable and what is not. At many institutions this has developed into categories of journals, such as an A-list, B-list, etc. These lists are often based upon published ranking lists and are extremely important not only in determining faculty qualifications but also for retention and promotion decisions. Although maybe less regarded, conference publications are another method of intellectual contributions that can be evaluated for performance. To the best of our knowledge, no

*Corresponding Author 
rankings have been published on operations management conferences. The intent of this paper is to contribute in this area.

The paper is developed by first discussing different journal ranking systems. The type of ranking system provides insight into how conferences can be ranked. After this, the literature on conference rankings is discussed. This includes the selection of a method and what the result, i.e. the rankings, mean. This is followed by a discussion of university rankings which serve as a base for the conference rankings and subsequently the comparative findings for several operations management oriented conferences. Finally, some conclusions are drawn.

\section{Ranking Journals}

Before discussing conference rankings in section three, this section will first look at journal rankings. The methods for journal rankings can provide insight into how conferences can be ranked. There are three different types of methods for determining journal rankings. Each of these ranking systems has a different orientation which can lead to different ranking results. The three ranking systems are: based upon perceived relevance and quality, based upon citation, and based upon author affiliation.

\subsection{Perceived Relevance and Quality}

One system for ranking journals is using perceived relevance and quality. With this method, a group of people is identified as well as a set of journals. People are then asked through surveys how these journals score on relevance and how they score on quality. Examples of these type of rankings are provided by Barman et al. (1991), Barman et al. (2001), and Soterou et al. (1999).

One of the subjective elements in this type of ranking is the initial selection of the respondents. For example, if POMS members are surveyed about operations management oriented journals then this ranking might differ from a survey of the Operations Management Division members of the Academy of Management. This explains how journals can be ranked differently even though the same survey instrument is used for ranking purposes.

\subsection{Citation Based}

Another system for ranking journals is by looking at citations. This method is based upon determining which journals have been the most influential in a discipline. With this method a set of journals (set A) is identified for ranking purposes and additionally a set of journals (set B, which can overlap set A) is identified for citations analysis purposes. The articles in journal set $B$ are analyzed to determine which journals from set $A$ are referenced most often. This determines the ranking of the journals in set A. Examples of this type of ranking are provided by Goh et al. (1997) and Vokurka (1996).

One of the subjective elements in this type of ranking is the initial selection of the journals used for citation analysis (set B). For example, authors that use mathematical modeling approaches are likely to cite articles that are also mathematical modeling oriented. Therefore, if more mathematical modeling oriented journals are in set $\mathrm{B}$, then it is expected that mathematical oriented journals in set A will be referenced more often than nonmathematical oriented journals in set $\mathrm{A}$ and therefore will be ranked higher.

\subsection{Author Affiliation}

A third type of journal ranking is based upon author affiliation. This method is based upon ranking journals by examining who publishes in these journals and the affiliation of these authors. An example of this type of ranking, for operations management, is provided by Gorman and Kanet (2005).

One of the subjective elements in this type of ranking is the initial selection of author affiliations. In this system a ranking of affiliations is assumed and the journal ranking is based upon the relative number of authors from the ranked institutions.

\subsection{Conclusion on Journal Rankings}

Journal rankings have been determined to aid, among other things, tenure and promotion decisions by providing a sense of 'quality' of publications. There are at least three different methods for ranking journals. Each of these methods is based upon certain assumptions which influence the ranking outcome. In the discussion above, only highlights of pros and cons per method are provided to 
illustrate that there is not one best method but that each method has its limitations. More detailed information related to the issue of journal rankings and concerns about these rankings can be found elsewhere in the literature. For example, Theoharakis et al. (2007) found that operations management journal rankings are particularly influenced by differences between empiricists and modelers, the geographic location of researchers, membership of professional society, and the selfselection bias stemming from publishing in a specific journal. Adler and Harzing (2009) provide a more general discussion of academic rankings, including journals, and the dysfunctionality of current rankings. Nkomo (2009) also discusses problems with rankings of scientific journals. However, as stated by Worrell (2009: 129): “Like them or not, academic ranking systems are a reality, and they are not very likely to go away anytime soon." Hence, it is worthwhile to do research in this area.

\section{Ranking Conferences}

Although publications about journal rankings are relatively common, this is quite a different matter for conferences. Part of the problem with conferences is that conference attendance and conference publications serve more roles than just an intellectual contribution. For example, one motive to participate in an operations management conference can be to meet colleagues in the area of operations management. Other motives can be to learn about new developments in an area of interest, to satisfy publishing requirements, the specific conference theme is of specific interest, the review process, and the international nature (number of countries represented). Getting feedback and/or validation for on-going research can also be factors in the decision as well as the amount of time allocated for discussions. Lastly, in some instances, the specific location of the conference and the choice venue and related events can be an incentive to participate. Overall, it is therefore much harder to develop a conference ranking than developing a journal ranking due to the number of different factors involved for participation.

In this paper a ranking of conferences is developed based upon the assumption that it relates to scientific 'quality'. In other words, this assumption is similar to the system for ranking journals. Obviously, if these methods are used for a conference ranking then the concerns as expressed in section two for journal rankings apply here as well. The choice to focus on 'scientific quality' means that the ranking system is not comprehensive but instead should be viewed as a first step towards developing a more comprehensive ranking.

To the best of our knowledge, a ranking for operations management conferences has not yet been published. Nevertheless, some conference rankings in other disciplines have been published, in particular in the area of computer science. An example is provided by Citeseer (http:// citeseer.ist.psu.edu/impact.html.) This ranking is based upon the citation analysis method. Another ranking is provided by Computer Science Conference Ranking (http://www.cs-conferenceranking.org/). They use an estimated impact of conference that uses the following weights: $40 \%$ for citation of papers, $20 \%$ for quality of referees' reports, $20 \%$ for availability of resources for students, $10 \%$ for indexing and $10 \%$ for the percentage of conference papers that are accepted or appeared in reputable journals. This type of ranking combines some of the different types of motives for attending a conference, for example financial support for students and quality of papers. Much of the weight is contributed to the citation of papers similar to the citation method for journal rankings. A study by Mathis and Zech (1992) looked at regional economics conferences and ranked based upon two indicators. First, they looked at the proportion of papers that were subsequently published in journals and second, they looked at the number of economists from top-rated universities who participated. This latter aspect is similar to the author affiliation method.

In this paper the first attempt to rank operations management conferences is made. For this ranking, the intent is to stay focused rather than combine multiple aspects such as by Computer Science Conference Ranking. Combining different aspects introduces the aspect of weight. Determining weight is difficult because not all attendees attend a conference for the same reason and at this point not enough is known about the participants' motives. The primary focus will be one of 'quality'. This means a more limited scope. The advantage of this 
is that the ranking will be more straightforward. The disadvantage is that the ranking will only be relevant to those attendees who are interested in the quality aspect of a conference.

In this paper a choice is made to use the author affiliation method. Each method has pros and cons for ranking as described in section 2 . The advantage of the author affiliation method is that it gives an indication of who is attending these types of conferences. Author affiliations provide two indications for quality. First, with the underlying assumption that affiliation is related to quality research, the authors from these affiliations are expected to present high quality research. Second, it indicates that researchers from top-affiliates are interested in a particular conference which is, assuming that these researchers are mainly interested in high quality research from others as well, another indication that the conference is of high quality. Note that high quality is equated here with the quality of the papers.

\section{Step One: Developing a Ranking of Affiliations}

In order to develop a conference ranking list based upon author affiliation, it is a requirement to have a ranking list of affiliations for operations management. Some affiliation rankings exist. For example the Financial Times publishes regularly a ranking list of the top-100 full time global Master of Business Administration (MBA) programs. However, to determine a conference ranking for operations management, by utilizing the author affiliation index, a discipline specific ranking of affiliations is required, not a ranking of educational programs.

Business Week and U.S. News \& World Report publish these types of rankings but their rankings only include U.S. institutions (see for example U.S. News \& World Report, 2009). The School of Management at the University of Texas at Dallas provides a method for ranking operations management affiliations (see: http:// citm.utdallas.edu/utdrankings). Their system allows selecting a range of journals and then a ranking is determined by looking at who publishes in operations management journals for a specific time period. Seven journals were selected that were
Table 1. Top-10 operations management affiliations based on University of Texas system

\begin{tabular}{|c|l|c|}
\hline Rank & \multicolumn{1}{|c|}{ Affiliation } & Country \\
\hline 1 & University of Pennsylvania & USA \\
2 & Columbia University & USA \\
3 & University of Maryland at College Park & USA \\
4 & Duke University & USA \\
5 & Massachusetts Institute of Technology & USA \\
6 & Stanford University & USA \\
7 & INSEAD & France \\
8 & New York University & USA \\
9 & Michigan State University & USA \\
10 & University of Minnesota at Twin Cities & USA \\
\hline
\end{tabular}

considered appropriate for operations management. These also appeared in operations management journal rankings such as by Barman et al (2001). The seven journals were: Management Science, Operations Research, Journal of Operations Management, Manufacturing and Service Operations Management, Production and Operations Management, Academy of Management Journal and Academy of Management Review. This leads to a top-10 ranking as shown in table 1.

This ranking by the University of Texas has two disadvantages. First, the journals that were analyzed are all US-based journals, this might create a US bias in the affiliation ranking. Second, the list includes journals that are more operations research oriented than operations management oriented. Because of these concerns a new affiliation ranking is developed here based on US and European journals and primarily dealing with operations/manufacturing management.

Six journals were selected. Three were US-based journals (Journal of Operations Management, Production and Operations Management, and Manufacturing \& Service Operations Management) and three were European-based journals (International Journal of Operations and Production Management, Journal of Manufacturing Technology Management, and International Journal of Manufacturing Technology and Management). Similar to the method by the University of Texas, an analysis was made for articles published in these journals for the last six years, i.e. 2002-2007. For each article one 'point' was assigned to the affiliation of 
the author(s). So, if there was only one author, then the affiliation of this one author received one point. If an article had four authors from four different institutions, then each institution received 0.25 points.

Bengtsson et al. (1997) discussed the publishing gap between European and American management research. This gap is a gap a gap between methodological approaches. They state: "While European studies run the risk of being regarded as weird and "unscientific" by North Americans, many Europeans may feel that North American research leans too much towards rigorous but rather uninteresting statistical exercises" (Bengtsson et al., 1997: 473). It can therefore be expected that the USbased journals attract different types of authors than European-based journals based upon the methodological assumptions used by reviewers and editorial boards. The analysis will therefore not only determine an affiliation ranking based upon the combination of European and US journals but also separately look at the different geographical areas.

A total of approximately 1800 articles appeared in the six journals for the six year period. Authors from roughly 830 universities made contributions to those articles. For ease of the analysis only the top-100 institutions will be used for determining the conference rankings in section 5 . These lists can be found in appendix $\mathrm{A}$ (combined journals), appendix $B$ (US-based journals), and appendix C (Europeanbased journals). The top-10 of each list is provided in tables 2, 3 and 4 .

Table 2. Top-10 operations management affiliations based on US and European journals

\begin{tabular}{|c|l|c|}
\hline Rank & \multicolumn{1}{|c|}{ Affiliation } & Country \\
\hline 1 & Michigan State University & USA \\
2 & Cranfield University & UK \\
3 & Hong Kong Polytechnic University & China \\
4 & Columbia University & USA \\
5 & University of Minnesota & USA \\
6 & Arizona State University & USA \\
7 & Aalborg University & Denmark \\
8 & University of British Columbia & Canada \\
9 & Georgia Institute of Technology & USA \\
10 & Helsinki University of Technology & Finland \\
\hline
\end{tabular}

Table 3. Top-10 operations management affiliations based on US journals

\begin{tabular}{|c|l|c|}
\hline Rank & \multicolumn{1}{|c|}{ Affiliation } & Country \\
\hline 1 & Michigan State University & USA \\
2 & Columbia University & USA \\
3 & University of Minnesota & USA \\
4 & Georgia Institute of Technology & USA \\
5 & Arizona State University & USA \\
6 & University of Maryland & USA \\
7 & Indiana University & USA \\
8 & University of Padua & Italy \\
9 & University of Bradford & UK \\
10 & Duke University & USA \\
\hline
\end{tabular}

Compared to the top-10 list from the University of Texas which included only US-based universities, the top-10 list in table 2 is more international with only five US-based universities. This illustrates how including European-based journals influences the ranking that is achieved.

3 illustrates that if only US-based journals are included, the list becomes dominated by US-based affiliations. Appendix B provides a further illustration of this and for example 34 out of the top50 institutions in appendix B are US-based.

Table 4 shows an opposite effect as table 3, i.e., European journals are not dominated by authors from the US. The list is also not conclusive to European affiliations. Four out of the top-10

Table 4. Top-10 operations management affiliations based on European journals

\begin{tabular}{|c|l|c|}
\hline Rank & \multicolumn{1}{|c|}{ Affiliation } & Country \\
\hline 1 & Cranfield University & UK \\
2 & Aalborg University & Denmark \\
3 & Hong Kong Polytechnic University & China \\
4 & University of British Columbia & Canada \\
5 & Cardiff University & UK \\
6 & Aston University & UK \\
7 & Chalmers University of Technology & Sweden \\
8 & University of Granada & Spain \\
9 & Monash University & Australia \\
10 & University of Tokyo & Japan \\
\hline
\end{tabular}


affiliations are not from Europe. Twenty-eight out of the top-50 institutions in appendix $C$ are European-based.

Tables 2, 3 and 4 confirm Bengtsson et al. (1997) by demonstrating how US-based authors publish more in US-journals while European journals attract more European and other non-US-based authors.

\section{Findings}

The author affiliation index for conference $\mathrm{x}$ is computed based upon Gorman and Kanet (2005), as follows. Let $\mathrm{n}(\mathrm{i})$ is total number of authors for article I, A(i) is the number of authors for article I from the top university set, $\mathrm{B}(\mathrm{i})$ is the number of authors not from the top university set, $\mathrm{M}$ is the set of conference articles for conference $x$, then the author affiliation index for conference $\mathrm{x}$ is:

$$
A A I(x)=\frac{\sum_{i \in M} A(i) / n(i)}{\sum_{i \in M}[A(i)+B(i)] / n(i)}
$$

In other words, the author affiliation index is the ratio of authors from top-schools divided by the total number of authors that appear on papers. As indicated before, one element for conferences is also who attends the conferences. Earlier analysis for the annual US-based POMS conference (Steenhuis, de Bruijn and Gupta, 2006) as well as for the annual European based EurOMA conference (Steenhuis and de Bruijn 2006) has shown that in some cases over ten authors appear on a conference paper. To control for this aspect only the first author will be used. The first author affiliation index (FAAI) is computed as follows:

$$
F A A I(x)=\frac{\sum_{i \in M} A_{i}}{M}
$$

Where; $\operatorname{FAAI}(x)$ is first author affiliation index for conference $x . A_{i}$ is a first author from the top-100 affiliations and $\mathrm{M}$ is the total number of articles at conference i. For the analysis, the FAAI index is calculated for four conferences with a primary focus on operations management in the last six years. Although more conferences exist which include a focus on operations management, they often are not primarily or only focused on operations management but are also for example oriented towards quality management which makes the less comparable to the 'pure' operations management conferences. Examples of these types of conferences are the International Conference on Supply Chain Management and Information Systems (SCMIS), International Conference on Quality, Innovation and Knowledge (QIK), Decision Sciences (DSI), and the Australian and New Zealand Academy of Management (ANZAM).

The first two conferences are POMS and EurOMA which are annual conferences, specifically aimed at operations management and organized by respectively the US-based operations management society and the Europe-based European operations management association. In addition, an Asian conference is also analyzed. For this, the Operations and Supply Chain Management (OSCM) conference was selected. Lastly, a more general management oriented conference was added that has a specific operations track, i.e., the operations management division of the US based Academy of Management. The results are provided in table 5. For each year, and by category the highest FAAI score is highlighted.

Table 5 shows that for four of the years, the Academy of Management conference scored highest for the percentage of first authors from top-100 affiliations based on how many papers from those affiliations were published in the combined six journals. In the other two years the Production and Operations Management conference scored highest. For the percentage of first authors from top-100 affiliations based on how many papers from those affiliations were published in the three US-based journals, in three of the years the Academy of Management scored the highest while in the other three years, the Production and Operations Management Conference scored the highest. The EurOMA conference scored highest in four of the six years for the highest percentage of first authors from top-100 affiliations based on how many papers from authors from those affiliations were published in the three European journals. The Academy of Management conference scored highest in two of the 
Table 5. Conference FAAl scores for four conferences in six years based upon FAAl.

\begin{tabular}{|c|c|c|c|c|c|c|c|c|}
\hline \multirow{2}{*}{ Conference } & \multirow{2}{*}{ Year } & \multirow{2}{*}{$\begin{array}{l}\text { Total papers } \\
\text { presented }\end{array}$} & \multicolumn{3}{|c|}{$\begin{array}{c}\text { Papers with first authors from top-100 } \\
\text { affiliations }\end{array}$} & \multicolumn{3}{|c|}{ F A A I } \\
\hline & & & Combined & US & Europe & Combined & US & Europe \\
\hline AoM-OM & 2003 & 27 & 11 & 13 & 4 & 0.407 & 0.481 & 0.148 \\
\hline EurOMA & 2003 & 319 & 69 & 49 & 60 & 0.216 & 0.154 & 0.188 \\
\hline POMS & 2003 & 414 & 108 & 135 & 48 & 0.261 & 0.326 & 0.116 \\
\hline AoM-OM & 2004 & 29 & 12 & 14 & 7 & 0.414 & 0.483 & 0.241 \\
\hline EurOMA & 2004 & 213 & 60 & 37 & 57 & 0.282 & 0.174 & 0.268 \\
\hline POMS & 2004 & 525 & 113 & 133 & 73 & 0.215 & 0.253 & 0.139 \\
\hline AoM-OM & 2005 & 48 & 15 & 16 & 11 & 0.313 & 0.333 & 0.229 \\
\hline EurOMA & 2005 & 243 & 65 & 41 & 71 & 0.267 & 0.169 & 0.292 \\
\hline OSCM & 2005 & 150 & 13 & 8 & 17 & 0.087 & 0.053 & 0.113 \\
\hline POMS & 2005 & 550 & 164 & 212 & 73 & 0.298 & 0.385 & 0.133 \\
\hline AoM-OM & 2006 & 110 & 31 & 37 & 19 & 0.282 & 0.336 & 0.173 \\
\hline EurOMA & 2006 & 242 & 50 & 29 & 49 & 0.207 & 0.120 & 0.202 \\
\hline POMS & 2006 & 618 & 189 & 223 & 83 & 0.306 & 0.361 & 0.134 \\
\hline AoM-OM & 2007 & 92 & 27 & 23 & 24 & 0.293 & 0.250 & 0.261 \\
\hline EurOMA & 2007 & 304 & 60 & 32 & 50 & 0.197 & 0.105 & 0.164 \\
\hline OSCM & 2007 & 117 & 9 & 5 & 8 & 0.077 & 0.043 & 0.068 \\
\hline POMS & 2007 & 696 & 223 & 272 & 101 & 0.320 & 0.391 & 0.145 \\
\hline AoM-OM & 2008 & 92 & 37 & 44 & 29 & 0.402 & 0.478 & 0.315 \\
\hline EurOMA & 2008 & 241 & 59 & 47 & 55 & 0.245 & 0.195 & 0.228 \\
\hline POMS & 2008 & 668 & 198 & 222 & 116 & 0.296 & 0.332 & 0.174 \\
\hline
\end{tabular}

six years. However, it is noticeable that these were the two most recent years. The OSCM conference did not score highest in any of the rankings.

Overall, these findings confirm Bengtsson et al.'s (1997) observation about a transatlantic divide. That is, the US conference shows a higher FAAI score for affiliations ranked for US journals while the European conference shows a higher FAAI score for affiliations ranked for European journals. In table 6 the averages for each conference are shown.

Table 6. Average FAAl scores for four conferences

\begin{tabular}{|l|c|c|c|}
\hline \multirow{2}{*}{ Conference } & \multicolumn{3}{|c|}{ F A A I } \\
\cline { 2 - 4 } & Combined & US & Europe \\
\hline POMS & 0.283 & 0.341 & 0.140 \\
EurOMA & 0.236 & 0.153 & 0.224 \\
AoM-OM & 0.352 & 0.394 & 0.228 \\
OSCM & 0.082 & 0.048 & 0.091 \\
\hline
\end{tabular}

Table 6 shows that on average the Academy of Management conference shows the highest percentage of authors from the top-100 affiliations regardless of whether the ranking of affiliations is based upon the three US journals, the three European journals or their combination. It also shows that the OSCM conference scores the lowest. This is not surprising since this is an Asian conference and the number of Asian universities in the affiliation rankings is lower than US and European universities.

\section{Conclusions}

In this paper a first attempt has been made to develop a ranking list for operations management conferences. A review of the literature revealed that no such ranking list exists. One of the methods used to rank journals, which has also been used in other fields to aid the development of conference rankings, is the author affiliation index. A similar 
approach was used here but limited to the first author. To apply the author affiliation index, it was first necessary to develop an affiliation ranking list. This was done by selecting three US-based and three European-based operations and manufacturing oriented journals.

It was found that the AoM conference scored most often the highest on the FAAI. This indicates that when academics are looking for conferences in the field of operations management, and if they are primarily interested in the quality of papers that are presented, then based upon the FAAI, the AoM conference is the best conference to attend. Also, POMS conferences scored higher for the top-100 ranked affiliations based on the three US-based journals while EurOMA conferences scored higher in each of the years for the top-100 ranked affiliations based on the three Europe-based journals. This signifies that academics who publish in European-based journal tend to favour the Euroma conference more while academics who publish in the US-based journals tend to favour the POMS conference more. It also confirms that at conferences there is a transatlantic divide similar as for journals as indicated by Bengtsson et al. (1997) and also found by Theoharakis et al. (2007). The OSCM conference received lower FAAI scores than the other conferences but this can be explained by the base for ranking affiliations which is more biased towards US and European affiliations. Currently, the number of Asian journals that appear in any of the published journal rankings is limited. Once Asian journals become more recognized it would be worthwhile to include them in the analysis.

A limitation to this research was that it focused on 'scientific quality' of the conference. In order to develop a more comprehensive conference ranking system, other motives for attending conferences can be added to this approach in future research. One of the issues with this will be the weight that needs to be attributed to the different motives. Future research can also include other conferences. In that case an aspect that needs attention is the difference between conferences that are solely or primarily oriented on operations management versus conferences that have slightly different orientations such as operations research or management research or conferences that have multiple orientations for example an emphasis on quality management or information technology.

Lessons for the future are that the FAAI index is only as useful as the affiliation ranking that is used. The affiliation rankings that were used in this paper were very much oriented on US and European universities because they were determined by analyzing US-based and Europeanbased journals and therefore might have biased the findings towards the US and Europe based conferences compared to OSCM.

\section{Acknowledgement}

The authors would like to thank Audrey O'Connor from EurOMA for providing some of the data, Sushil Gupta from POMS for providing some of the data and for suggestions for improvement and an anonymous reviewer for helpful comments for improvement. We also want to thank Jeff James, Kodo Yokozawa, Simon Zomerdijk and Steven Jansen and in particular Courtney Fleming and Krystal King for their help with the data analysis.

\section{References}

Adler, N.J. and Harzing, A.W. (2009), When knowledge wins: transcending the sense and nonsense of academic rankings, Academy of Management Learning and Education, 8(1), pp. 72-95.

Barman, S., Tersine, R.J. and Buckley, M.R. (1991), An empirical assessment of the perceived relevance an quality of POM-related journals by academicians, Journal of Operations Management, 10(2), pp. 194-212.

Barman, S., Hanna, M.D. and LaForge, R.L. (2001), Perceived relevance and quality of POM journals: a decade later, Journal of Operations Management, 19, pp. 367-385.

Bengtsson, L., Elg, U. and Lind, J.I. (1997), Bridging the transatlantic publishing gap: how North American reviewers evaluate European idiographic research, Scandinavian Journal of Management, 13(4), pp. 473-492.

Goh, C.H., Holsapple, C.W., Johnson, L.E. and Tanner, J.R. (1997), Evaluating and classifying POM journals, Journal of Operations Management, 15, pp. 123-138.

Gorman, M.F. and Kanet, J.J. (2005), Evaluating operations management-related journals via the author affiliation index, Manufacturing E Service Operations Management, 7(1), pp. 3-19. 
Mathis, E.J. and Zech, C.E. (1992), The quality of regional economics conferences, Eastern Economic Journal, 18(2), pp. 221-228.

Nkomo, S.M. (2009), The seductive power of academic journal rankings: challenges of searching for the otherwise, Academy of Management Learning E Education, 8(1), pp. 106-112.

Soteriou, A.C., Hadjinicola, G.C. and Patsia, K. (1999), Assessing production and operations management related journals: the European perspective, Journal of Operations Management, 17, pp. 225-238.

Steenhuis, H.J., Bruijn, E.J. de and Gupta, S. (2006), Location analysis of POMS conference contributions, presented at the $17^{\text {th }}$ Annual POMS conference, Boston, April 28May $1^{\text {st }}$.

Steenhuis, H.J. and Bruijn, E.J. de (2006), Location analysis of EurOMA conference contributors, EurOMA 2006, Moving up the value chain, Vol. II, 18-21 June, Glasgow, Scotland, pp. 435-443.
Theoharakis, V., Voss, C. Hadjinicola, G.C. and Soteriou, A.C. (2007), Insights into factors affecting Production and Operations Management (POM) journal evaluation, Journal of Operations Management, 25, pp. 932-955.

U.S. News \& World Report (2009), The top business schools, U.S. News \& World Report, 146(4), pp. 66-68.

Vokurka, R.J. (1996), The relative importance of journals used in operations management research, A citation analysis, Journal of Operations Management, 14, pp. 345355.

Worrell, D.L. (2009), Assessing business scholarship: the difficulties in moving beyond the rigor-relevance paradigm gap, Academy of Management Learning $\mathcal{E}$ Education, 8(1), pp. 127-130. 
Appendix A: Top-100 affiliations based upon number of publications in six selected journals

\begin{tabular}{|c|c|c|c|}
\hline Rank & Affiliation & Country & Score \\
\hline 1 & Michigan State University & USA & 32.84 \\
\hline 2 & Cranfield University & UK & 26.08 \\
\hline 3 & Hong Kong Polytechnic University & China & 23.16 \\
\hline 4 & Columbia University & USA & 20.76 \\
\hline 5 & University of Minnesota & USA & 20.50 \\
\hline 6 & Arizona State University & USA & 19.66 \\
\hline 7 & Aalborg University & Denmark & 19.42 \\
\hline 8 & University of British Columbia & Canada & 16.67 \\
\hline 9 & Georgia Institute of Technology & USA & 15.49 \\
\hline 10 & Helsinki University of Technology & Finland & 15.34 \\
\hline 11 & Cardiff University & UK & 15.24 \\
\hline 12 & Aston University & UK & 13.25 \\
\hline 13 & Indiana University & USA & 12.33 \\
\hline 14 & University of Maryland & USA & 12.33 \\
\hline 15 & University of Granada & Spain & 12.08 \\
\hline 16 & Chalmers University of Technology & Sweden & 11.83 \\
\hline 17 & University of London & UK & 11.33 \\
\hline 18 & University of Louisville & USA & 11.24 \\
\hline 19 & University of Padua & Italy & 11.17 \\
\hline 20 & Monash University & Australia & 11.00 \\
\hline 21 & University of Tokyo & Japan & 11.00 \\
\hline 22 & University of New Hampshire & USA & 10.00 \\
\hline 23 & Nanyang Technological University & Singapore & 9.16 \\
\hline 24 & University of Bradford & UK & 9.16 \\
\hline 25 & University of Melbourne & Australia & 9.16 \\
\hline 26 & $\begin{array}{l}\text { Sri Ramakrishna Mission Vidyalaya } \\
\text { Polytech }\end{array}$ & India & 9.00 \\
\hline 27 & National Chiao Tung University & Taiwan & 8.92 \\
\hline 28 & University of Salamanca & Spain & 8.91 \\
\hline 29 & Duke University & USA & 8.83 \\
\hline 30 & University of Bologna & Italy & 8.74 \\
\hline 31 & University of Oslo & Norway & 8.67 \\
\hline 32 & Pisa University & Italy & 8.66 \\
\hline 33 & University of Western Ontario & Canada & 8.58 \\
\hline 34 & University of Manchester & UK & 8.33 \\
\hline 35 & Eindhoven University of Technology & The Netherlands & 8.30 \\
\hline 36 & University of Valencia & Spain & 8.25 \\
\hline 37 & Ohio State University & USA & 8.24 \\
\hline 38 & Stanford University & USA & 8.17 \\
\hline 39 & Ghent University & Belgium & 8.00 \\
\hline 40 & Harvard University & USA & 8.00 \\
\hline 41 & University of Calgary & Canada & 7.83 \\
\hline 42 & Texas A\&M University & USA & 7.58 \\
\hline 43 & University of Texas - Dallas & USA & 7.58 \\
\hline 44 & University of Sussex & UK & 7.57 \\
\hline 45 & Manchester Metropolitan University & UK & 7.50 \\
\hline 46 & Thunderbird & USA & 7.50 \\
\hline 47 & University of South Dakota & USA & 7.50 \\
\hline 48 & Massachusetts Institute of Technology & USA & 7.49 \\
\hline 49 & Pennsylvania State University & USA & 7.41 \\
\hline 50 & University of Pennsylvania & USA & 7.33 \\
\hline
\end{tabular}

\begin{tabular}{|c|c|c|c|}
\hline Rank & Affiliation & Country & Score \\
\hline 51 & University of Ulster & UK & 7.33 \\
\hline 52 & Erasmus University Rotterdam & The Netherlands & 7.16 \\
\hline 53 & INSEAD & France and Singapore & 7.16 \\
\hline 54 & Cornell University & USA & 6.91 \\
\hline 55 & University of Virginia & USA & 6.83 \\
\hline 56 & University of Cincinnati & USA & 6.74 \\
\hline 57 & University of South Carolina & USA & 6.74 \\
\hline 58 & Linkoping University & Sweden & 6.67 \\
\hline 59 & Clemson University & USA & 6.66 \\
\hline 60 & National Cheng Kung University & Taiwan & 6.50 \\
\hline 61 & University of Tampere & Finland & 6.50 \\
\hline 62 & University of Toledo & USA & 6.50 \\
\hline 63 & University of Victoria & Canada & 6.50 \\
\hline 64 & DePaul University & USA & 6.49 \\
\hline 65 & McGill University & Canada & 6.42 \\
\hline 66 & New York University & USA & 6.41 \\
\hline 67 & Lund University & Sweden & 6.33 \\
\hline 68 & Northwestern University & USA & 6.25 \\
\hline 69 & Lappeenranta University of Technology & Finland & 6.17 \\
\hline 70 & North Carolina State University & USA & 6.01 \\
\hline 71 & Boston College & USA & 5.99 \\
\hline 72 & University of Arkansas & USA & 5.99 \\
\hline 73 & City University of Hong Kong & China & 5.91 \\
\hline 74 & Brunel University & UK & 5.83 \\
\hline 75 & University of Applied Sciences & Germany & 5.83 \\
\hline 76 & Wake Forest University & USA & 5.83 \\
\hline 77 & National Sun Yat-sen University & Taiwan & 5.75 \\
\hline 78 & Northern Illinois University & USA & 5.75 \\
\hline 79 & Emory University & USA & 5.74 \\
\hline 80 & National Chengchi University & Taiwan & 5.58 \\
\hline 81 & University of Cambridge & UK & 5.58 \\
\hline 82 & University of Auckland & New Zealand & 5.50 \\
\hline 83 & University of Geneva & Switzerland & 5.50 \\
\hline 84 & University of Warwick & UK & 5.42 \\
\hline 85 & National University of Singapore & Singapore & 5.33 \\
\hline 86 & University of Nebraska & USA & 5.33 \\
\hline 87 & University of Florida & USA & 5.17 \\
\hline 88 & University of Laval & Canada & 5.16 \\
\hline 89 & University of Siena & Italy & 5.00 \\
\hline 90 & University of California & USA & 4.99 \\
\hline 91 & University of Memphis & USA & 4.75 \\
\hline 92 & Copenhagen Business School & Denmark & 4.67 \\
\hline 93 & $\begin{array}{l}\text { Hong Kong University of Science } \\
\text { and Tech }\end{array}$ & China & 4.66 \\
\hline 94 & University of Magdeburg & Germany & 4.66 \\
\hline 95 & National Tsing Hua University & Taiwan & 4.58 \\
\hline 96 & University of California at Los Angeles & USA & 4.50 \\
\hline 97 & University of Rochester & USA & 4.50 \\
\hline 98 & Renssleaer Polytechnic Institute & USA & 4.49 \\
\hline 99 & Kansas State University & USA & 4.43 \\
\hline 100 & Rutgers University & USA & 4.41 \\
\hline
\end{tabular}


Appendix B: Top-100 affiliations based upon number of publications in three US-based journals

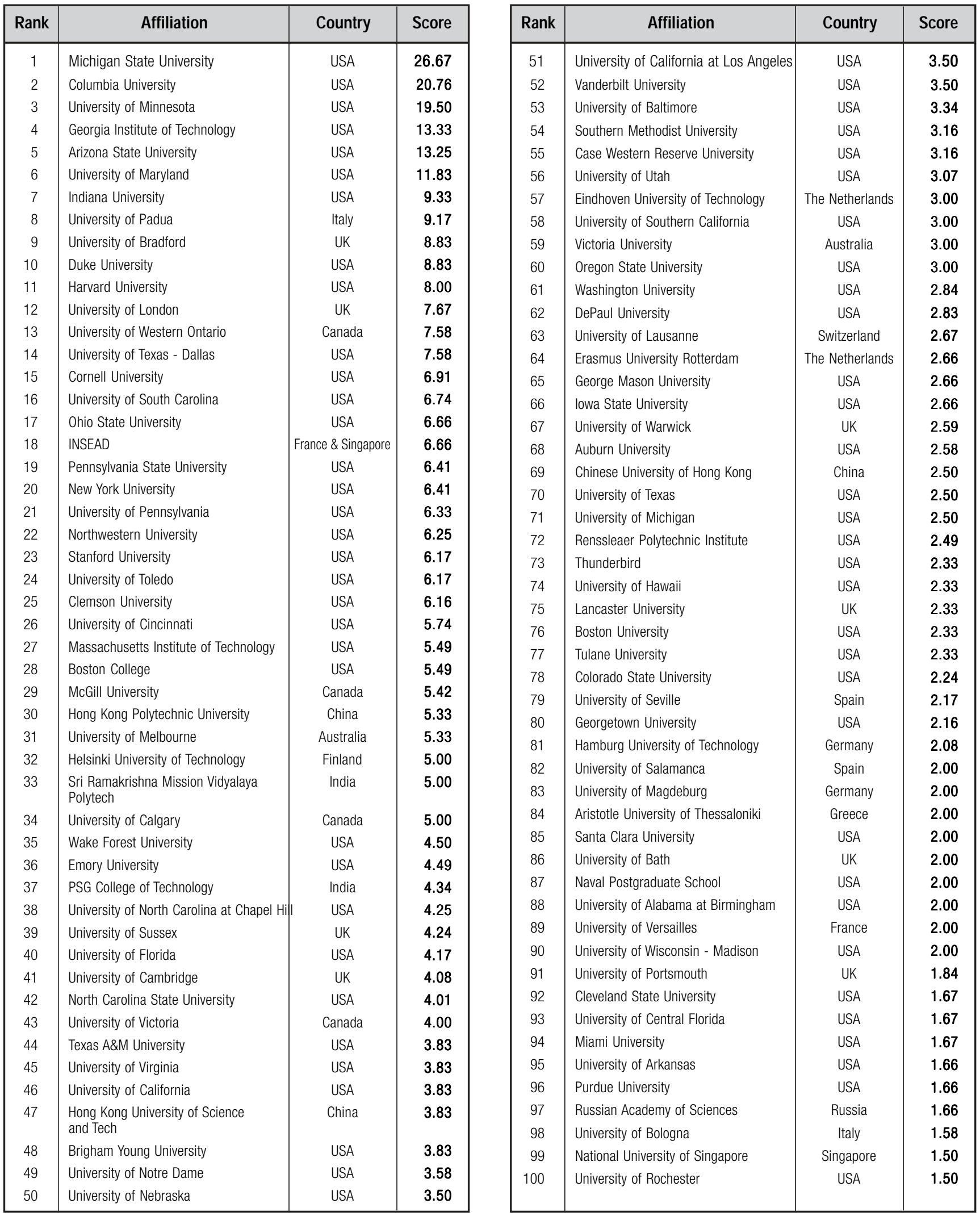


Appendix C: Top-100 affiliations based upon number of publications in three European-based journals

\begin{tabular}{|c|c|c|c|}
\hline Rank & Affiliation & Country & Score \\
\hline 1 & Cranfield University & UK & 25.08 \\
\hline 2 & Aalborg University & Denmark & 19.42 \\
\hline 3 & Hong Kong Polytechnic University & China & 17.83 \\
\hline 4 & University of British Columbia & Canada & 16.67 \\
\hline 5 & Cardiff University & UK & 13.83 \\
\hline 6 & Aston University & UK & 13.00 \\
\hline 7 & Chalmers University of Technology & Sweden & 11.83 \\
\hline 8 & University of Granada & Spain & 11.08 \\
\hline 9 & Monash University & Australia & 11.00 \\
\hline 10 & University of Tokyo & Japan & 11.00 \\
\hline 11 & University of Louisville & USA & 10.91 \\
\hline 12 & Helsinki University of Technology & Finland & 10.34 \\
\hline 13 & University of New Hampshire & USA & 9.50 \\
\hline 14 & National Chiao Tung University & Taiwan & 8.92 \\
\hline 15 & University of Oslo & Norway & 8.67 \\
\hline 16 & Nanyang Technological University & Singapore & 8.66 \\
\hline 17 & Pisa University & Italy & 8.66 \\
\hline 18 & University of Valencia & Spain & 8.25 \\
\hline 19 & Manchester Metropolitan University & UK & 7.50 \\
\hline 20 & University of South Dakota & USA & 7.50 \\
\hline 21 & University of Manchester & UK & 7.33 \\
\hline 22 & University of Ulster & UK & 7.33 \\
\hline 23 & University of Bologna & Italy & 7.16 \\
\hline 24 & Ghent University & Belgium & 7.00 \\
\hline 25 & University of Salamanca & Spain & 6.91 \\
\hline 26 & National Cheng Kung University & Taiwan & 6.50 \\
\hline 27 & University of Tampere & Finland & 6.50 \\
\hline 28 & Arizona State University & USA & 6.41 \\
\hline 29 & Michigan State University & USA & 6.17 \\
\hline 30 & Linkoping University & Sweden & 6.17 \\
\hline 31 & Lappeenranta University of Technology & Finland & 6.17 \\
\hline 32 & Brunel University & UK & 5.83 \\
\hline 33 & University of Applied Sciences & Germany & 5.83 \\
\hline 34 & National Sun Yat-sen University & Taiwan & 5.75 \\
\hline 35 & National Chengchi University & Taiwan & 5.58 \\
\hline 36 & University of Auckland & New Zealand & 5.50 \\
\hline 37 & University of Geneva & Switzerland & 5.50 \\
\hline 38 & Eindhoven University of Technology & The Netherlands & 5.30 \\
\hline 39 & Thunderbird & USA & 5.17 \\
\hline 40 & University of Laval & Canada & 5.16 \\
\hline 41 & Lund University & Sweden & 5.00 \\
\hline 42 & Northern Illinois University & USA & 5.00 \\
\hline 43 & University of Siena & Italy & 5.00 \\
\hline 44 & City University of Hong Kong & China & 4.91 \\
\hline 45 & Copenhagen Business School & Denmark & 4.67 \\
\hline 46 & National Tsing Hua University & Taiwan & 4.58 \\
\hline 47 & Erasmus University Rotterdam & The Netherlands & 4.50 \\
\hline 48 & Kansas State University & USA & 4.43 \\
\hline 49 & University of Arkansas & USA & 4.33 \\
\hline 50 & University of Rome & Italy & 4.17 \\
\hline
\end{tabular}

\begin{tabular}{|c|c|c|c|}
\hline Rank & Affiliation & Country & Score \\
\hline 51 & Sri Ramakrishna Mission Vidyalaya Polytec & India & 4.00 \\
\hline 52 & Mannheim University & Germany & 4.00 \\
\hline 53 & University of Western Australia & Australia & 4.00 \\
\hline 54 & University of Melbourne & Austria & 3.83 \\
\hline 55 & National University of Singapore & Singapore & 3.83 \\
\hline 56 & University of Connecticut & USA & 3.83 \\
\hline 57 & Texas A\&M University & USA & 3.75 \\
\hline 58 & University of Memphis & USA & 3.75 \\
\hline 59 & University of Southern Denmark & Denmark & 3.75 \\
\hline 60 & University of Tokushima & Japan & 3.74 \\
\hline 61 & Open University & UK & 3.67 \\
\hline 62 & University of London & UK & 3.66 \\
\hline 63 & DePaul University & USA & 3.66 \\
\hline 64 & Loughborough University & UK & 3.66 \\
\hline 65 & $\begin{array}{l}\text { WHU - Otto-Beisheim Graduate School } \\
\text { of Management }\end{array}$ & Germany & 3.50 \\
\hline 66 & Deakin University & Australia & 3.50 \\
\hline 67 & Delft University of Technology & The Netherlands & 3.50 \\
\hline 68 & Federal University of Rio grande do Sul & Taiwan & 3.50 \\
\hline 69 & Long Island University & USA & 3.50 \\
\hline 70 & Nottingham University & UK & 3.50 \\
\hline 71 & University of Leeds & UK & 3.50 \\
\hline 72 & University of the Mediterranean & France & 3.50 \\
\hline 73 & University of Sussex & UK & 3.33 \\
\hline 74 & Indian Institute of Technology & India & 3.33 \\
\hline 75 & Seoul National University of Technology & Korea & 3.33 \\
\hline 76 & University of La Verne & USA & 3.33 \\
\hline 77 & $\begin{array}{l}\text { National Kaohsiung First University } \\
\text { of Science and Technology }\end{array}$ & Taiwan & 3.25 \\
\hline 78 & University of Southern Maine & USA & 3.25 \\
\hline 79 & Chung-Yuan Christian University & Taiwan & 3.17 \\
\hline 80 & University of Bielefeld & Germany & 3.17 \\
\hline 81 & Rutgers University & USA & 3.16 \\
\hline 82 & Florida Atlantic University & USA & 3.16 \\
\hline 83 & University of Twente & The Netherlands & 3.08 \\
\hline 84 & Indiana University & USA & 3.00 \\
\hline 85 & University of Virginia & USA & 3.00 \\
\hline 86 & University of Rochester & USA & 3.00 \\
\hline 87 & University of Brighton & UK & 3.00 \\
\hline 88 & Huazhong University of Science and Tech & China & 3.00 \\
\hline 89 & Universidad Complutense de Madrid & Spain & 3.00 \\
\hline 90 & University College of Boras & Sweden & 3.00 \\
\hline 91 & University of Gavle & Sweden & 3.00 \\
\hline 92 & University of Montreal & Canada & 3.00 \\
\hline 93 & Bradford University & UK & 2.84 \\
\hline 94 & University of Calgary & Canada & 2.83 \\
\hline 95 & University of Warwick & UK & 2.83 \\
\hline 96 & University of Ottowa & Canada & 2.83 \\
\hline 97 & Michigan Technological University & USA & 2.83 \\
\hline 98 & University of Nottingham & UK & 2.83 \\
\hline 99 & University of Pompeu Fabra & Spain & 2.83 \\
\hline 100 & University of Thessaly & Greece & 2.83 \\
\hline
\end{tabular}


Harm-Jan Steenhuis is an associate professor of Operations Management at Eastern Washington University and Chair of the Department of Management. He received his MSc in Industrial Engineering and Management and his PhD in International Technology Transfer from the University of Twente, the Netherlands. He is currently involved in research on international technology transfer and manufacturing, industry-university technology transfer and instructor-student knowledge transfer.

Erik J. de Bruijn is a professor of International Management. He received his MSc from the University of Massachusetts and a PhD from the University of Twente. Since 1971 he worked as project coordinator and consultant in various industrialization projects in developing countries. Currently he teaches International Business Management at the School of Management and Governance, University of Twente. 